\title{
DATA BASE USER LANGUAGES FOK THE NON-PROGRAMMER
}

Peter C. Lockemann

Fakultaet fuer Informatik, universitaet karlsruhe

D-75 Karlsruhe 1

\section{Abstract}

In light of the necessary investments, comercially available data base systems usually offer comparatively general-purpose interfaces. These are suitable only for the data base specialist. In order for a aata base system to attract non-programer users, interfaces must be provided that approximate the special user terminology and conceptualizations. If, in particular, these users form a heterogeneous group, a variety of interfaces will be required. Questions of interest are then the extent to which user interfaces should be standardized, the techniques which allow rapia implementation of new more specialized interfaces, or the procedure for selecting the most suitable interface for a given problem. Based on the concept of hierarchy of abstract machines, the paper presents a possible approach to the solution of these questions. Three examples will be introduced to critically examine the concept and demonstrate some of its merits anö shortcomings. 


\section{Introduction}

The success or fallure of a data base system, no matter how well-conceivea it may appear to the author's mind, is ultimately decided by the users the systeni is supposed to serve. This aspect is otten overlooked by system planners who devote almost their entire effort towaras organizational problems such as analyzing the informational needs of an institution or organization, the current status of information flow within the organization and the necessary improvements to it. From the analysis a number of requirements are derived such as the extent of information integration, time characteristics, information system structure, adaptation of the organizational structure, relinquishment of old resources and provision of new ones. All too often, much less attention is being paia to the indiviouals who must use the system. They are simply expected to appreciate the needs of the organization and to adapt most willingly to the new environment.

Human nature, however, is conservative Human individuals will cling to the same terminology and methodology and try to solve the same problems unless and until one can make a most convincing point for reorientation. In many cases data base systems are not even introducea to solve new kinds of problems. Rather they are supposed to improve the solution to existing and already well-understood problems, or at least use these problems as a point of departure. Under these circumstances there is no reason why users snould te turdened with radical changes in style.

unfortunately, for the manufacturer of a data base system this is just one side of a coin. For him, the development and implementation of a data base system represents a large investment which he can only justify by corresponding sales figures. This precludes him from attending to each of a large variety of individual user needs but compels him to offer general-purpose interfaces. On the other hand it is these general-purpose interfaces that prove repugnant to many a potential user who has his own special terminology, conceptualizations and application problens.

In order to resolve the dilema, techniques must be developed that permit the adaptation of a data base system to various user needs. In particular, the solutions should adaress themselves to the following questions.

(i) How can user language interfaces be separated from the operational and management characteristics of the data base system? 
(ii) Are there any techniques that allow, in a systematic way, for the rapid implementation of a user language according to given specitications?

(iii) To which extent is it economically feasible to construct and stockpile "off-the-shelf" user languages?

(iv) Given a set of language specifications, unaer which conditions can one build upon an already existing user language? Can one define a relation on user languages that formalizes these conditions and determines the amount of effort required?

To answer these questions we shall define a hierarchical relationship between user languages. The nature of the relationship will be discussed in some detai1. A number of examples will be introduced to explicate the approach and to point out its merits as well as some of its present shortconings. The discussion is intended basically for non-procedural interactive languages.

\section{Hierarchies of user languages}

\subsection{Concepts}

Ihe hierarchy of language interfaces shall be defined as follows lKr 75] :

- Each interface is defined in terms of a ("lower") interface, and may itself serve as the basis for definition of a ("higher") interface.

- There is exactiy one interface which cannot be defined in terms of another interface and hence serves as the ultimate basis for all other interfaces.

Such a hierarchy of interfaces may be graphically represented in the form of a tree where each node corresponas to a particular interface.

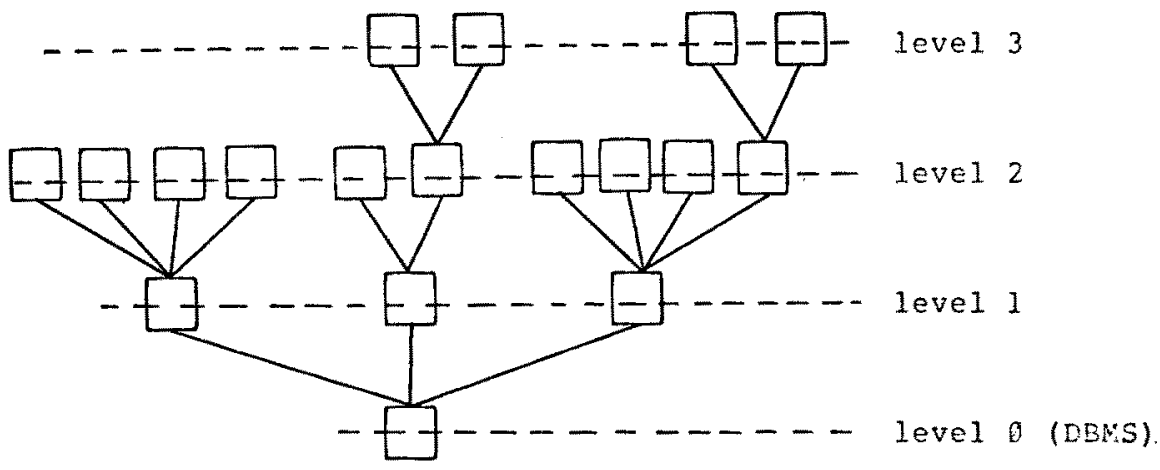


The hierarchy must be chosen such that it reflects a hierarchy of users. Level corresponds to the data base specialist, while level 3 might cater to a user completely untrained in computer affairs.

The previous questions can now be restated with a little bit more precision.

(i) Can all fundamental operational and management functions be solved underneath the basis on level 0 ?

(ii) What are the formal criteria that allow to construct a hierarchy by defining new languages in terns of existing ones?

(iii) Up to which level in the tree should interfaces be standardized? (iv) Suppose a given language specification is represented as a node. can a path to an existing node be constructed, and the length of the path be "measured" Can one aetermine the path with minimum length? It the path is too long, should intermediate nodes be introduced, and what would be their specifications?

At this point in time, "length" is no more than an intuitive notion for which a formal measure does not exist. However, a rough outline of the definition of one node in terms of another one may often give some insight into the amount of effort necessary and thus provide an estimate of the length.

Language hierarchies have long been mentioned in connection with programing languages, e.g. Assembler - Low-level programming languages (e.g. PL 366 [Wi 68], ESPOL [EU 72]) - High-level programming languages - very high level languages (e.g., set oriented languages [SI 74]). However, except for macro languages these do rarely conform to the strict definition given above (e.g. CoBOL is not aefined in terms of a lower-level programming language), the reason being that this would entail ineficient compilation. The same argument does not hold for data base languages where language analysis is but a minor part of query processing [Kr 75].

\subsection{Explications}

Whe notion of hierarchy as introduced above is still vague and should be made more precise. Below several concepts known from the literature are introduced. Their usefulness as well as some of their deficiencies will be discussed in the remainder of the paper. 
(1) Characteristics of the root.

There exist several schools that claim to provide the just and only basis for data base concepts. Before one may pass any judgment on these claims one ought to agree on the criteria that a basis would have to meet. It is commonly accepted that a data base is to be considered as the model of a certain reality. Hence a basis should be such that it provides concepts so primitive that any reality, be it physical or conceptual, could be adequately covered by it. Some authors [Ab 74, Su 74] have attempted to enumerate certain primitives: elementary objects, properties, relations, orderings, categories for types), names, as well as sets of operators for creating, accessing, manipulating and deleting these. In addition, one might consider organizational questions such as parallelism and sharing of models by various users.

(2) Dependencies between successive nodes.

Since it is extremely general, the root is of little practical value to the average user. Users are invariably concerned not with all possible realities but with certain classes of realities, and wish their models to reflect the corresponding limitations. In other words, the modeling tools on level 1 will aiffer from those on level $\theta$ by defining certain restrictions on the way the primitives may interact. The same obviously is true for level 2 vis-a-vis level 1 , etc. These restrictions relate mainly to the manner in which objects may be composed into new objects, relations into new relations, and/or operations into new operations.

(3) Characterization of a node as an abstract machine.

Basically, the restrictions defined on the permissible compositions determine the dependencies between successive nodes. To make this a little bit more precise, the concept of abstract machine is introduced. An abstract machine is a set of object types, a set of operators for manipulating objects and defined on object types, together with a control mechanism that allows to construct and execute sequences of operations. Each node is then described in terms of an abstract machine.

(4) Dependencies between abstract machines.

By assigning an abstract machine to each node, the following properties must hold between two successive nodes $A_{i}$ and $A_{i+1}$ [Go 73]: 
a) The resources and the functions provided by $A_{i}$ form the complete basis on which to build $A_{i+1}$. There is no way to use properties of $A_{i-1}$ in building $A_{i+1}$. Hence every $A_{i}$ is a complete interface description in the hierarchy.

b) Resources of $A_{i}$ used in defining new resources of $A_{i+1}$ can no longer be present in $A_{i+1}$ ( $i . e$. they may become resources of $A_{i}+1$ only it they are not part of a definition for another resource of $\left.A_{i+1}\right)$.

Keeping these rules in mind I shall attempt, as a matter of illustration, a tentative classification of some results discussed in the literature $[A B$ 74, Co 70 , We $74, \operatorname{Kr} 75$, Wo 68, Wo 73, Gr 69, Col $68]$.

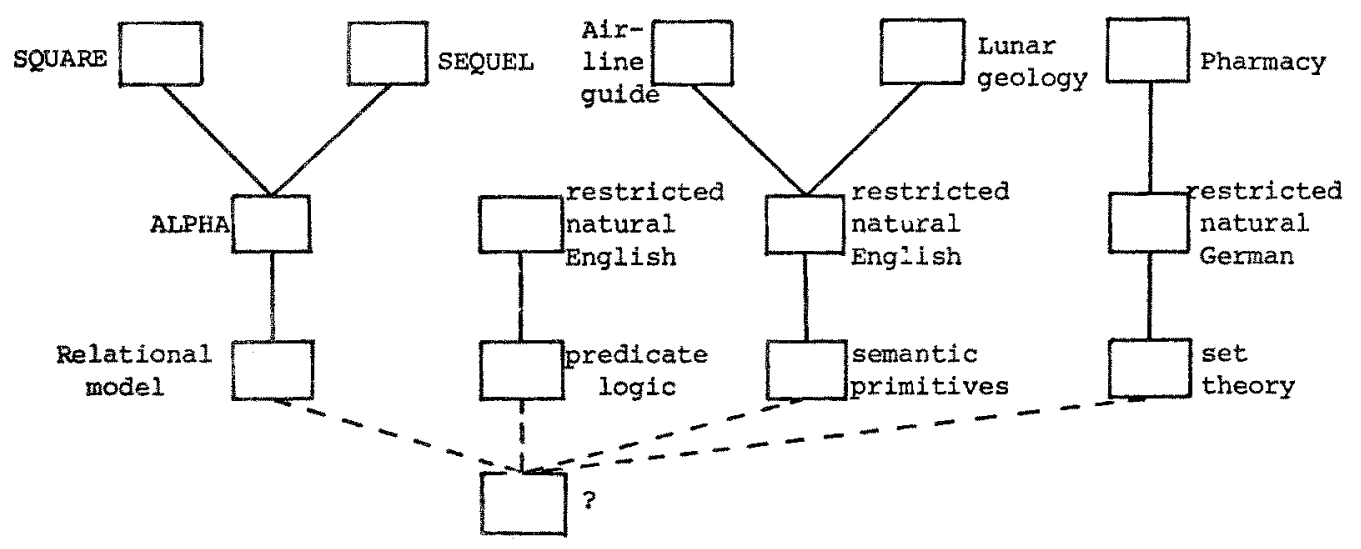

figure 2

\subsection{Consequences}

The concepts and rules introduced above impose a certain discipline on the design of user languages, on their application, and on the transition between them. Some of the consequences are outlined below.

(1) If we strictly keep to the rules above, a new interface must be defined in terms of its immeaiate predecessor and not any arbitrarily chosen predecessor, i.e. immediate predecessors must not be bypassed ("stepwise abstraction"). On the other hand, given certain specifications and a suitable node in a tree, intermediate nodes that hopefully are of general usefulness should be introduced on the intervening path whenever the path proves too "long" ("stepwise refinement"). 
(2) Given a path to the root, a user should be put into position - at least in principle - to formulate his requests in any of the languages that correspond to the nodes on the path. As a matter of fact, we found this an essential prerequisite for eficient system testing since system activities may be observed and controlled to any desired level of detail [Kr 75].

(3) Queries are stated on some level and must successively be translated between levels until the root has been reached. Definition (of an abstract machine) and translation reciprocate each other: The definition of the next higher level from a given one determines the rules that govern the translation of statements on the higher level to those on the lower level.

(4) Results are produced on the lowest level but must be presented to the user on a higher level. As a consequence, following the evaluation of a query a second ("reverse") translation must be invoked in order to propagate the results to higher levels.

\section{Set theoretic basis}

\subsection{Motivation}

The rules of ch.2 have been applied to the construction of the KAIFAS question-answering system and have proven highly useful there. Hence this system will be chosen as the first example to demonstrate the practicability of the rules. For a more detailed description of the system the reader is referred to the literature [Kr 75].

Restrictions with regard to the general basis are motivated by the realities one wishes to consider. In the case of RAIFAS we presume that relations are exclusively of the property type (sets) or are binary relations and, more important, that objects are selected exclusively on the basis of given properties or relations which they meet or undergo, perhaps in logical combination. Indeed one can show that the set theoretic approach may be viewed as a generalization of the inverted file technique [ $\mathrm{Kr} 75]$. 


\section{object_types}

I Elementary objects (indivicuals), e.g. Bans Maier, Bonn, Aspirin

W sets, e.g. city, medication

List of individuals.

R Relations, e.g. Lather, contraindication List of ordered pairs of indiviauals.

8 Numbers

D Measures, e.g. 2 years, 4 tablets/ày ordered pairs (number, unit expression).

$F$ Weasure functions, e.g. age, cosage Lists of oraered n-tuples whose last components are measures.

B rruth values

\section{pperators}

On retrieval the machine is supposed to function in the following way. Set, relation, and function names refer to objects in permanent storage. In order to manipulate the objects they must be transferred into unnamed registers of which an unlimited number is thought to exist. Hence all operations except for the load operations are register-to-register operations.

Load operators ww, ev, en, ef

Load a set, a relation (ev, en), and a measure Eunction, respectively.

Set operators

MU: $M x i y \rightarrow$ union

Wn: $M x \rightarrow M-1$ Intersection

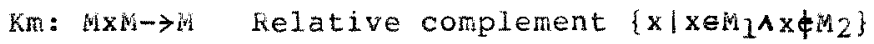

kz: $\quad M \rightarrow z \quad$ Carainality

Binary relation operators

Ko: $\quad k \rightarrow R$ Converse relation

$\mathrm{Rb}: \mathrm{Rx} \rightarrow \mathrm{R}$ kestriction $\{(\mathrm{x}, \mathrm{y}) \mid(\mathrm{x}, \mathrm{y})$ ekAxeh

$R p: R x h \rightarrow R$ eroouct $\left\{(x, y) \mid \exists z:(x, z) \in R_{1} \wedge(z, y) \in R_{2}\right\}$

$R U: R \times R \rightarrow R$ Union

Reduction of binary relations

Vo: $\quad K \rightarrow M$ Domain $\{x \mid \exists y:(x, y)$ eK $\}$ 


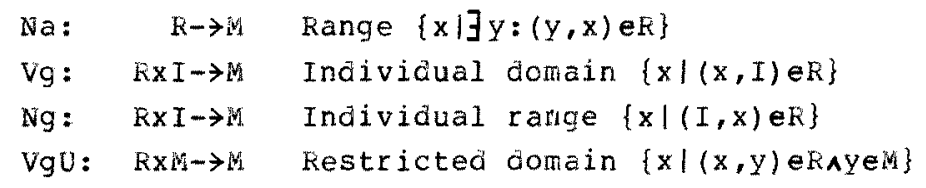

\section{Reauction of measure functions}

FW: FXI $\rightarrow D \quad(n=2)$

\section{Logical operators}

$\begin{array}{lll}\text { e: } & \text { I } X M \rightarrow B & \text { Test on set membership } \\ c: & \text { W } & \end{array}$

In adition, the standard logical operators are available as well as the stanciard arithmetic and comparison operators for numbers and measures.

\section{Control mechanis}

\section{Sequencing of operations}

"Programs" for the set theoretic machine are expressed in a functional notation. Operations are performed from left to $x$ ight and, for each nested argument, from inside out.

Example: A question such as "Are cities birthplaces of engineers?" would take the following form in the set theoretic machine

$c\left(N w\left(M_{c i t y}\right), V g U\left(e n\left(R_{b i r t h p l a c e)}, W w\left(M_{e n g i n e e r}\right)\right)\right.\right.$ )

\section{Loops}

Loops are introduced by the use of bounded quantifiers which have three arguments:

1) An expression resulting in a set of objects (range).

2) An expression for the condition resulting in a truth value (scope); it may be regarded as the loop body.

3) The name of a bound variable; each of its substitutions defines an invocation of the loop.

Important quantifiers are

AL: $M \times B \rightarrow B$ all, every

$E I: M \times B \rightarrow B$ some

$D B: M \times B \rightarrow M$ which 
$\angle B: M \times B \rightarrow Z$ how many

with tre leit-hand $\mathrm{M}$ the bouming set and the left-hand $\mathrm{B}$ the concition.

Examples:

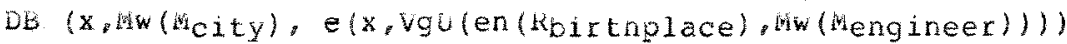

with the meaning of "Which cities are birtnplaces of engineers"

$\mathrm{DB} \quad$ (XI.

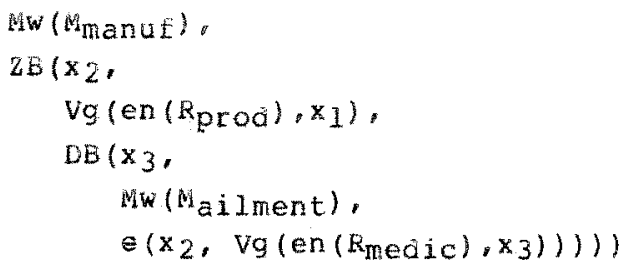

with the meaning of "How many products of wich manufacturers are medications for which ailments?"

Expressions in the data base

Set membership of an arbitrary kind is expressed by including, in the representation of a set, arbitraxy set expressions. Example in German):

\begin{tabular}{|l|}
\hline \multicolumn{1}{|c|}{ Mrezeptpflichtig } \\
\hline Ispasmocibalgin \\
Vg(en (Roerivat), Ioxazolioin) \\
IMorphin (Mopiate) \\
Mw(Mypnotika) \\
IMethadon \\
Vg(en(RDerivat), Isuccinimic) \\
Vg(en(Rheilnittel), IAgitiertheit)
\end{tabular}

where (1) indicates all derivates of oxazolidin to be prescription arugs, (2) all opiates, etc.

Whis concept is extended to relations and measure functions. Two of its advantages are:

- Since all objects are evaluated on request only, changes to the data base may be made locally without regard to any interrelationships that may exist. 
- Expressions may be stored without regard for the existence of any indiviauals for it. Hence one could construct a data base consisting exclusively of higher-order relationships.

One consequence, however, is that the control mechanism must itself be defined recursively since it may be invoked on any load operation.

\subsection{Natural language}

Few users will feel at ease with the highly stylized language introduced in sec. 3.2. One possible step of abstraction, therefore, is the definition of a new abstract machine accepting natural language input. By necessity this is a highly restricted form of natural language since its semantics, and hence its syntactic forms, can be no more than what may ultimately be reauced to a set theoretic interpretation. Moreover, it must be considered more restrictive than the set theoretic interface because while one may nest set theoretic expressions to an arbitrary depth, those beyond a certain depth simply cannot be stated in natural language in any comprehensible fashion.

To speak of objects, operators and control mechanism in connection with natural language turns out to be highly unnatural, or rather impossible. It is possible, however, to define an abstract machine on that level in terms of the syntax of the interface which in turn may still be based on object types. This is in striking similarity to very High Level languages vis-a-vis High Level programming languages: Very High Level languages are loosely described as languages used to specify what is to be done, rather than how it is to be done [SI 74].

In accoraance with sec.2.2, the object types must relate to the ones of the set theoretic machine. In this case the relationship is straightforward as indicated by the following list:

N proper names for the objects of the universe.

A attributes (properties of an object of the universe).

$R$ references from one object of the universe to a second one (e.g. Thebacon is referrea to by Morphium as its derivate).

$M$ references to measures.

D numbers or measures.

$S$ sentences. These are of two kinds: sentences to be answered by yes or no, and sentences to be answered by counting or enumerating proper names. 
some examples trom malfas in which German was chosen as natural language interface.

Ist Psyquil rezeptptichtig?

iN

A

Betraegt die $\frac{\text { Tagesoosis }}{W} \frac{\text { Chinidin }}{N} \frac{2 \text { arama }}{\mathrm{N}}$

Welche Derivate von Morphium sinc rezeptetichtig.

K

The syntax of the interlace is describea by a gramar witu the rollowing general properties:

(1) Syntactical variables must relate to the object types, nence they cannot be based on the traditional gramatical categories sucn as noun, noun phrase, acjective, etc. but on categories tnat are essentially semantical in nature. The variables are in (names), wí (attributes), Ra (references), witreferences to measures), za (numbers), SA (sentences), Qu (quantiliers).

(2) On the other hand, the traditional categories must be accounted for in some way, e.g. in order to reject incorrect inflections. As a conseguence, each syntactical variable is indexed oy a number of reatures. Examples:

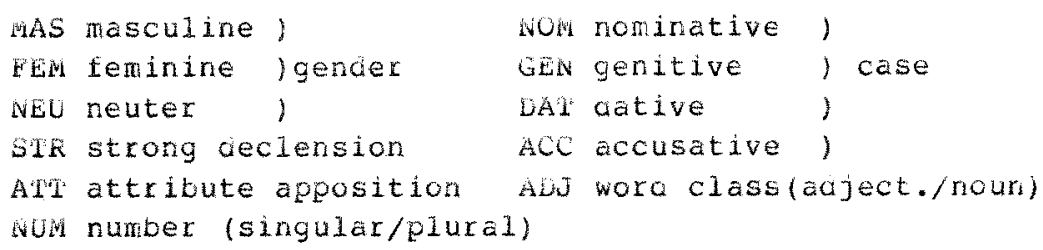

(3) Even for restricted hatural language, gramars are known to be extremely complex because of the multituce of syntactic aspects to be observea. The application of features simplifies the gramar insofar as it can be arranged in two levels,

a) a context-free gramar in terms of the variables from (1):

b) feature program to be associated with each production on level a).

Example: rypical productions of level a) are

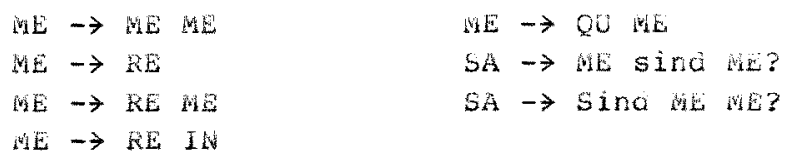


whe production

$M E_{1} \rightarrow M_{2} M E_{3}$

refers to the following feature program (syntactic variables are numbered for reference).

Part 1: Test of $\mathbf{r}$ ight-hand features for acceptance

(reauction takes place only if the condition is true).

test $\left(\mathrm{ME}_{2},+\mathrm{ADJ}+\mathrm{ATH}\right)$ A test $\left(\mathrm{ME}_{3},-\mathrm{ADJ}-\mathrm{AI} \mathrm{H}\right)$

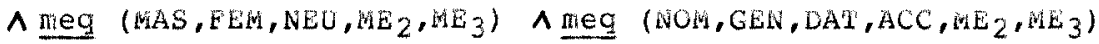

$\wedge$ equ (Nuin, $\left(\mathrm{HE}_{2}, \mathrm{HE}_{3}\right)$

Part 2: Assignment of features to the syntactic variable on the left-hanò side.

$-A D J-A F T, \subseteq O P\left(N U M, M E_{2}\right)$,

and (MAS, EEM, NEU, $\mathrm{ME}_{2}, \mathrm{ME}_{3}$ ), and (NOM, GEN, DAT, ACC, ME $2, \mathrm{ME}_{3}$ )

Feature operators are underlinea. For example, test is true when the features of the first argument meet the condition specified by the second argument. meg is true whenever at least one of the Iisted features agree in both syntactic variables specified. cop copies the features of the syntactic variable specified.

\subsection{Pharmacology}

The natural language level is supposed to serve a variety of application areas. We postulate that these application areas are all served by the same natural language gramar since each must be explainable in terms of set theory. Consequently, these areas aiffer only in the vocabulary they assign to the object types. Level 3 is reached from level 2 simply by introducing names, and relating them to the object types. Eelow a few typical examples of assigniment are given in the area of pharmacology.

\begin{tabular}{|c|c|}
\hline proper names & $\begin{array}{l}\text { medications, substances, companies, ailments, } \\
\text { e.g. Thebacon, Horphium, CrBA, Angina pectoris }\end{array}$ \\
\hline attributes & $\begin{array}{l}\text { properties } \\
\text { e.g. Tablette, rezeptpflichtig }\end{array}$ \\
\hline references & $\begin{array}{l}\text { e.g. Indikation and Rontraindikation (from ailment to } \\
\text { medication), Hersteller (from company to medication) }\end{array}$ \\
\hline $\begin{array}{l}\text { references } \\
\text { to measures }\end{array}$ & e.g. Preis, Dosis, Haltbarkeit \\
\hline $\begin{array}{l}\text { numbers or } \\
\text { measures }\end{array}$ & e.g. 5 Dif, 2 Tabletten/Tag, 4 wochen \\
\hline senterices & $\begin{array}{l}\text { e.g. Welche preise haben praeparate, die bei Angina } \\
\text { pectoris indiziert sind una deren Kontraindikation nicht } \\
\text { Glaukom ist? }\end{array}$ \\
\hline
\end{tabular}


The pata between adjacent nodes is traversed by transiation (sec.2.3, (3) and (4)). We shall briefly illustrate this for the passage between natural and set language. In this case translation consists of the three tracitional phases: lexical analysis, syntactic analysis ano code generation. The sentence

"welche Firmen sind Hersteller tablettenfoermiger wedikamente?" shall serve as an example.

Lexiçal analysís

Lexical analysis includes the mapping from the pharmacological to the natural language level, ana for each wora encounterea, with a few exceptions, proceeds in three steps:

(i) reduction of a word to its word stem;

(ii) dictionary lookup resulting in a syntactical variable, values of some of its features, anc a norphenic class, as well as the set level name for the word.

(iii) assignment of further features on the basis of the morphemic class and the actual morphemic ending.

The lexical analysis of the entire sentence results in

\begin{tabular}{|c|c|c|c|}
\hline word & $\begin{array}{l}\text { Isyn. } \\
\text { Ivar }\end{array}$ & features & $\left.\right|_{1} ^{\text {Int.name }}$ \\
\hline \multicolumn{4}{|c|}{ 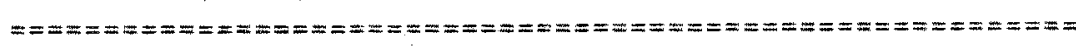 } \\
\hline welche & Qu & $1+M A S+E E N+N E O-N O M+N O N+A C C$ & $1 \quad \mathrm{LE}$ \\
\hline Firmen & $1 \mathrm{ME}$ & I $\mathrm{EEN}-\mathrm{NUW}+\mathrm{NOM}+\mathrm{GEN}+\mathrm{DAT}+\mathrm{ACC}$ & 1126 \\
\hline sind & $1-$ & - & $1-$ \\
\hline \multirow{2}{*}{ Hersteller } & I RE & $+\mathrm{NAS}+\mathrm{NU}+\mathrm{NOW}+\mathrm{DAT}+\mathrm{ACC}$ & $1 \mathrm{R} 23$ \\
\hline & $\mathrm{RE}$ & $+M A S-N O M+N O M+G E N+A C C$ & 1 \\
\hline tabletten- & $1 \mathrm{AE}$ & $+M A S+N O M+N O M+A I I+S T R+A D J$ & 1 \\
\hline \multirow[t]{2}{*}{ foermiger } & $1 \mathrm{ME}$ & $1+F E M+N U M+G E N+D A T+A T+S T R+A D J$ & 1149 \\
\hline & 1 枯E & $1+M A S+E E U+N E U-N U M+G E N+A T T+S T R+A D J$ & \\
\hline Meaka- & $1 \mathrm{ME}$ & I +NEU-NUM+NOM+GEN+ACC & 1422 \\
\hline mente & 1 & & 1 \\
\hline$?$ & $1-$ & - & 1 \\
\hline
\end{tabular}

Note the syntactic ambiguities due to the difierent leature combinations for "Hersteller" and "tablettenfoermiger'. Note also tnat lexical analysis by itself cannot always deternine the case las for Eirmen", all four cases are still possible), or the gencer (as tor 'tablettentoermiger"). 


\section{Syntactic anaiys}

Syntactic analysis includes three phases: reduction (level a)), feature analysis (level b)), final code manipulation. for each proauction applied, reauction and feature analysis follow each other immediately. Hence a production is applied in three steps:

(i) Matching of input string and right-hand side.

(ii) rest of right-hand features for acceptance.

(iii) If true, reduction to left-hand side and assignment of features.

For example, the production and feature program from sec.3.3 result in the following when applied to the phrase "tablettenfoermiger Medikamente":

ME2 ('tablettenfoermig'):

1) $+M A S+N O W+N O H+A T+A D J$ (rejected on meg)

2) $+\mathrm{EEH}+\mathrm{KU} W+\mathrm{GEN}+\mathrm{DAT}+\mathrm{ATW}+\mathrm{AQJ}$ (rejectea on meg)

3) + $\mathrm{HAS}+\mathrm{EEH}+\mathrm{NEO}-\mathrm{NU}+\mathrm{GEN}+\mathrm{ATT}+\mathrm{ADJ}$

ME3 ('Medikamente')

1) $+\mathrm{NEU}-\mathrm{NUN}+\mathrm{NOM}+\mathrm{CEN}+\mathrm{ACC}$

MEl (result):

1) $+\mathrm{NEO}+\mathrm{GEN}-\mathrm{NUM}-\mathrm{ADJ}-\mathrm{ATT}$

(note the disambiguation)

The syntactic analysis of the entire sentence is illustrated in figure 3. Because of the possibility of ambiguities the result is a parsing graph rather than a tree (in this case the ambiguity of the sentence is due to "Hersteller"). The numbers aajacent to the syntactic variables refer to an associated list of features.

Final code manipulation is left to the final stages of code generation, but must be considered part of the syntactic analysis because without it context-sensitive or transformational rules could not be avoided.

\section{Coge_generation}

whenever a production is applied, a semantic action associated with it generates a functional set expression. Its arguments point to other such expressions unless they are indiviauals.

Example:

(tablettenfoermiger Meaikamente)

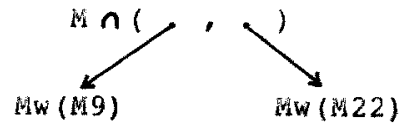

(tablettenfoermig) (Medikament) 


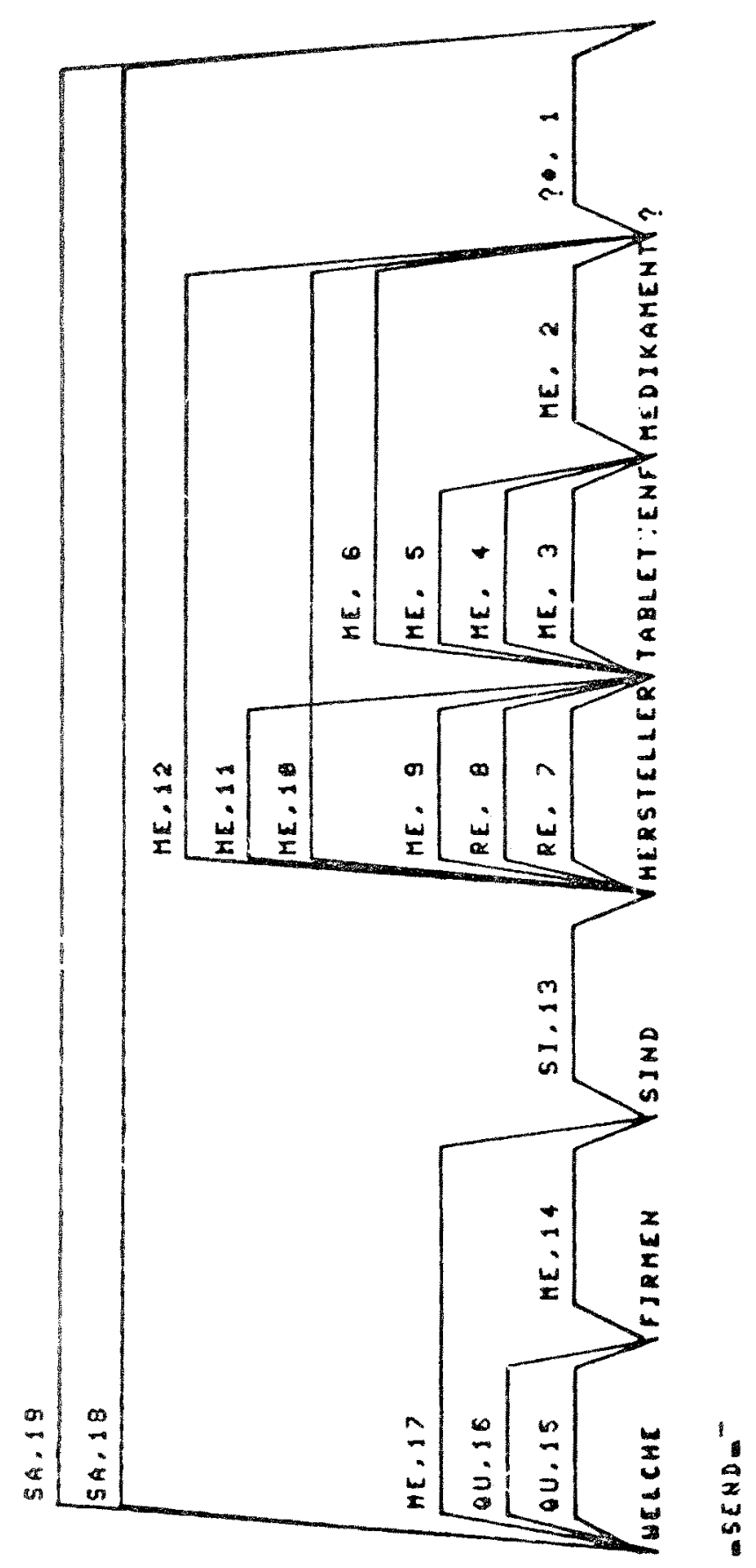


WELCHE FIRMEN SIND HERSTELLER TABLETTENFOERMIGER MEDIKAMENTE ?

\begin{tabular}{|c|c|c|c|}
\hline $\begin{array}{l}02300047 \\
10000001\end{array}$ & $\begin{array}{l}15000000 \\
01100025\end{array}$ & $\begin{array}{l}D B \\
X 1\end{array}$ & ' \\
\hline 15000000 & 14000005 & 6 & $M-T(5)$ \\
\hline 01100033 & 15000000 & $M W$ & 6 \\
\hline 04000032 & 16000000 & $\$ 26$ & ; \\
\hline 16000000 & 01200001 & ) & $\varepsilon$ \\
\hline 15000000 & 10000001 & 6 & $\times 1$ \\
\hline 01100025 & 15000000 & $A A$ & $c$ \\
\hline 14100026 & 01100045 & $M-T(22)$ & $M V *$ \\
\hline 15000000 & 01200040 & $r$ & $\operatorname{Va*}$ \\
\hline 15000000 & 01100030 & ( & EN \\
\hline 15000000 & 05000027 & 1 & R23 \\
\hline 16000000 & 01200044 & r & MD \\
\hline 15000000 & 01100033 & 1 & $M W$ \\
\hline 15000000 & 04000033 & 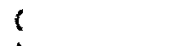 & 427 \\
\hline 16000000 & 01100033 & 2 & $M W$ \\
\hline 15000000 & 04000026 & ( & M22 \\
\hline 16000000 & 16000000 & 1 & ) \\
\hline 16000000 & 16000000 & ) & ? \\
\hline 16000000 & 16000000 & ) & ) \\
\hline 26000000 & 00000000 & EHIRBE & -- \\
\hline
\end{tabular}


On completion of the parse, the pointer structure corresponding to the syntactic variable $\mathrm{SA}$ is transformed into a linear string. This string must be subritted to a further string manipulation for two reasons.

(1) Completion of the syntactic analysis. Quantifiers do not yet appear in front of the expression. doving them there is subject to a number of rules that govern their sequence.

(2) optimization.

In many cases quantifiers (whose evaluation may be time-consuming) can be replaced by standara set or relation operators, e.g. DB by Wn.

The coce resulting from translation of the sentence above is shown in the printout in tigure 4.

Reverse translation

Set level names may immediately be translated into the pharmaceutical level simply by again invoking the aictionary. However, under certain conditions (empty sets) set expressions may themselves be part of a result. Whis requires a translation into both level 2 and level 3. Examples:

Vg(RI2, I14) $\rightarrow$ heilnittel fuer Psychosen

Mw (M9) $\rightarrow$ tablettenfoermig

I2 $\rightarrow$ Verophen

\section{Semantic primitives as a basis}

\section{I Motivation}

In order to stuay tne adequacy of the rules of ch.2 ana to determine whether they must be further refined or augmented it is nelpful, snort of constructing systems, to examine existing systems that are arranged in the form of layers. One of the olcest systems of this kind (though it was not conceived that way) is woods question-answering machine [wo 68, wo 73]. Iike the set theoretic approach, woods' universe is composed of objects and interrelationships between them. unilike the previous approach, these are not collected into mathematical sets and relations but treated as propositions to which a procedural approach is taken. This is probably due to an orientation towaras explaining the semantics of natural language rather than manipulating concrete data bases. 


\subsection{Semantic primitives}

\section{object_types}

O Elementary objects, e.g. Boston, $A A-57, D C-9,8: 00$ a.m.

$\mathrm{F}^{\mathrm{n}} \mathrm{n}$-ary functions $(\mathrm{n}>1)$, e.g. departure time (of flight $\mathrm{x}_{1}$ for place $x_{2}$ ). These need not be functions in the strict sense. If a function may yield more than one value (e.g. officer of a ship) it is defined as a successor function such that

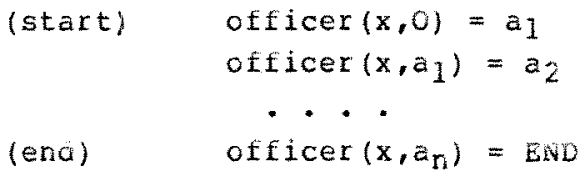

$k^{n} n$-ary relation (predicate) $(n \geqslant 1)$, e.g. Jet (filght $x_{1}$ is a jet), arrive (flight $x_{1}$ goes to place $x_{2}$ ).

D Designators are either names of elementary objects or of the form $F^{n}\left(x_{1}, \ldots, x_{n}\right)$ where $x_{i}$ is a designator; e.g. departure time $(A A-57$, Boston) for $8: 00$ a.m.

P Fropositions $R^{n}\left(x_{1}, \ldots, x_{n}\right)$ where $x_{i}$ is a designator; e.g. jet $(A A-57)$, place (Boston), arrive (AA-57, Chicago).

B Truth values

Example: A set of semantic primitives for the flight schedules table (from [Wo 68]):

\section{Primitive predicates}

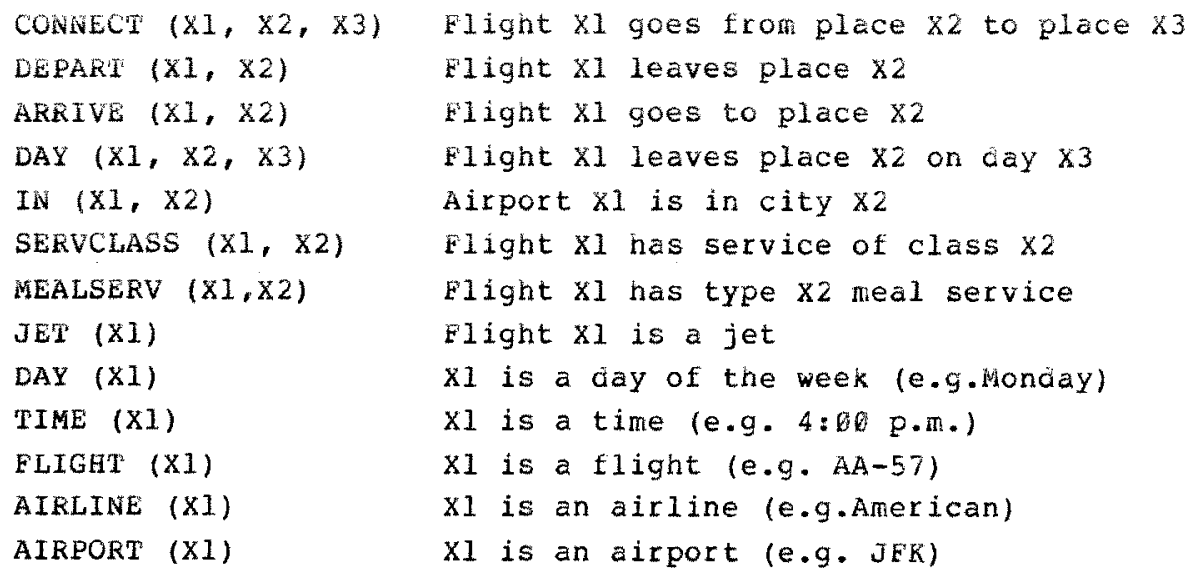




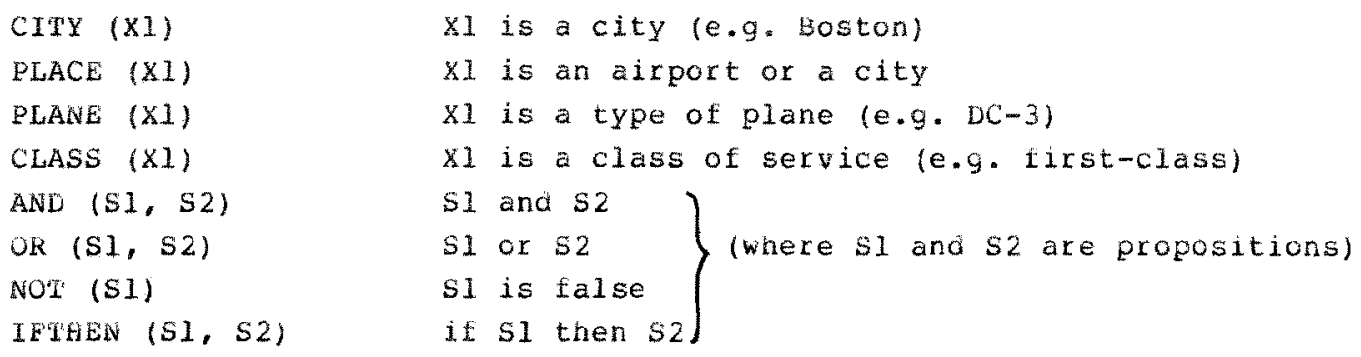

\section{Primitive functions}

DHIHE $\left(\mathrm{X}_{1}, \mathrm{X} 2\right)$

AIIME $(X I, X 2)$

the departure time of 11 ight $x 1$ trom place $\times 2$

NUMSTOPS $(\times 1, \times 2, \times 3)$

the arrival time of flight $x 1$ in place $x 2$

the number of stops of flight $x l$ between place

$\times 2$ and place $\times 3$

OWNER $(X I)$

the airline which operates flight $x i$

EQUIP (XI)

the type of plane of flight $x 1$

FARE $(X 1, \times 2, \times 3, \times 4)$

the cost of an $x 3$ type ticket from place $x 1$ to place $x 2$ with service of class $x 4(e .9$. the cost of a one-way ticket from Boston to chicago with first-class service)

\section{operatorg}

To every function and relation there exists a programea subroutine (procedure) which cetermines a value of a function or the truth of a proposition.

Examples (procedure names are capitalizew):

JET $(A A-57) \rightarrow$ true

ARRIVE (AA-57,Chicago) $\rightarrow$ true

ARRIVE (AA-57, Doston) $\rightarrow$ talse

DIIME (AA-57, woston) $\rightarrow 8: 00$ a.m.

whereas the abstract machine of ch. 3 was based on object types but specific operators, the abstract machine in this case is defined in terms of both object and operator types. Specific instances must be supplied by the user for both of them. However, with the aavent of microprograming, compater scientists should have little problems in adjusting to this kind of notion.

Control mechanism

As in the preceoing example, programs are expressed in functional notation, e.g. 
TEST (CONNECI (AA-57, BOSTON, CHICAGO))

woula stana for "Does AA-57 go from Boston to Chicago?". Likewise, queries of any appreciable degree of complexity are based on the notion of bounded quantifier as a representative for loops.

Ihe format for a quantified expression is

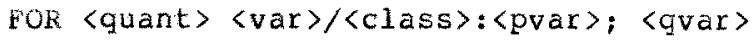

where

〈quant> a type of quantifier (EACH, EVERY, SOME, ThE, NMANY). 〈var〉 a bound variable.

<class> class of objects over which quantification is to range. The specification is performed by special enumeration functions, e.9. SEQ, DATALINE, NUMBER, AVERAGE. Besicies enumeration these functions may perform searches or computations.

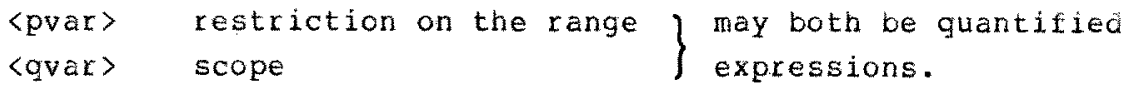

Unlike RAlFAs where the result of the evaluation of an expression is automaticaliy retranslated and displayed, this must be explicitiy requested by commanos such as TEst (test truth of a proposition), PRINIOUT (print the representation for a designator).

Examples:

(FOK EVERY XI / (SEQ TYPECS):T; (PKINTOUT (X1))

prints the sample numbers for all the lunar samples which are of

type C rocks, i.e. breccias (T stancis for "true").

(TEST (FOR 30 MANY X1 / (SEQ FLIGHT):JET(XI); DEPART (XI, BOSTON)))

"Do 3 jet flights leave Boston?"

\subsection{Natural language}

As a general rule, the introductory remarks to sec.3.3 appiy here as well: The level of the "English-like" query language provided on level 2 is influenced by the range of expressions possible on the previously discussed level 1. In contrast to RAIFAS, inspection of the data base is not Iimited to the evaluation of level 1 expressions but may take place during translation from level 2 into level 1, too. The semantic actions associated with a rule of gramar impose further restrictions, e.g. they make sure that the first argument of ConsEcI is indeed an instance of the class FLIGHT. 
This is illustrated by the following example. In a first step a syntactic analyeis is performed and a phrase marker is derived, e.g.

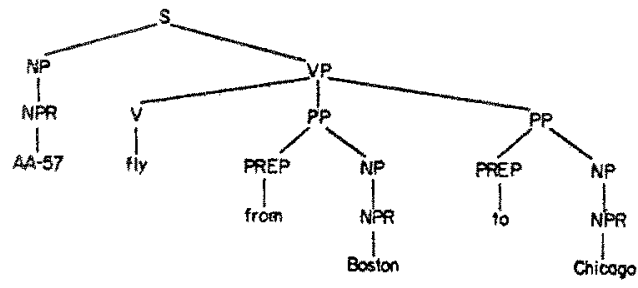

Since verbs in knglish correspono roughiy to preaicates, ana noun phrases are used to derote the arguments of the preaicate, the vero in the phrase marker will be the primary factor in determining the preaicate. In the example, the predicate will be connecr. For this it is necessary that the subject be a flight and that there be prepositional phrases whose objets are places representing origin (from) ano destination (to). The gramatical relations anong elements of a phrase marker are defined by partial tree structures, e.g.

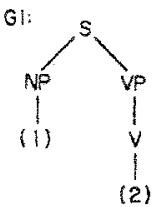

Subjetserb

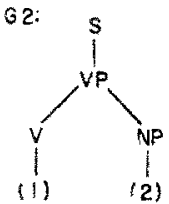

verb-object

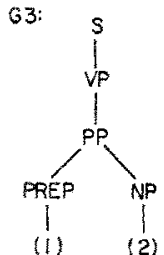

preposition object modifying o $\vee P$

Among the tiree structures, GI and G3 botn match subtrees in the phrase marker. Which of these is acceptable depenas on the aciational rules, e.g.

(GI:FLIGHI (1) and $(2)= \pm 1 Y$ ).

(11) and (2) are positional variables in the partial tree structure). Ihis rule obviously is satisfied. More complex rules are possibje; for example, the topnost s-nocie of the phrase marker is matchea by the rule

$1-(G 1:$ FLIGH ((1)) and $(2)=f l y)$ and

$2-(63:(1)=$ trom and PLACE (2))) and

$3-(63:(1)=$ to and $\operatorname{PLACE}((2)))$

$\Rightarrow \quad \operatorname{CoNheCr}(1-1,2-2,3-2)$ 


\subsection{Airline guide}

The system under aiscussion was first applied to a flight schedules table. ro illustrate the application interface, a lew exmples of queries shall be given below (from [wo 68]).

Does American Airlines have a flight which goes from Eoston to Chicago?

what is the departure time from Boston of every American Airlines flight that goes from Boston to Chicago?

what American Airlines flights arrive in Cnicago from Boston before $I: 00$ p.m.?

How many airlines have more than 3 flights that go from Boston to Chicago?

\subsection{Lunar geology}

Hore recentiy the system has been appliea to access, compare ano evaluate the chenical analysis data on lunar rock and soil composition that was accumulating as a result of the Apollo missions [wo 73]. Examples:

What is the average concentration of aluminum in high alkali rocks? Give me all analyses of 516046 ! How many breccias contain olivine? Do any samples have greater than 13 percent aluminum? what is the average model concentration of ilmenite in type A rocks?

\subsection{Critigue}

(1) The possibility of inspecting the data base both on level 1 and during translation from level 2 to level 1 introuluces a note of confusion. Since, according to sec.2.3, translation is directly related to definition, the translation process must make no reference to the data base. The lack of separation will have practical repercussions: Either certain changes on level 1 will necessitate changes in the rules of gramar, or parts of the control mechanisi for level 1 must be duplicated for transiation purposes.

(2) In woods system the subroutines co not appear to verity that their arguments are of the proper kind (E.g. ARRIVE does not check whether $A A-57$ is inceed a flight or chicago a place), since this 
is done on translation. If one left this (correctiy) to level 1 then prinitive predicates and functions are related to each other. these interdependencies may be expressed by a set of axions, or in the parlance of data structures by types or categories corresponding to those unary predicates that restrict ranges ot arguments. As a consequence, the concepts ol abstract machine ano relationships between abstract machines nust account not only for primitive terms but for axions as weil. Wote that the kAIrAs machine circumvents this problem only by prescribing ali operators.)

(3) Operators (subroutines) ana objects are interaependent as well. albeit in a one-to-one fasnion. In oroier to make sure that the requirements governing the relationship between abstract machines are met it suffices to treat a predicate or function and its corresponajig procedure as two instances of the same resource.

5 Relational model

\subsection{Motivation}

One of the most widely alscussed approaches to cata bases is loud"s relational model [Co 70,00 72, we 74$]$ which lends itsel particularly well to an interpretation by abstract machines. Coau supposes his users to explain tneir universe in terms ot table-like structures. Intuitively speaking, a table consists of a number of entries that are cormatted in exactiy the same way a sequence of ilelos orcerea on certain heacings or fielo names or, as they are callea nere, attributes. More formally, a entry is an oroered n-tuple and, consequentIy, a table is a relation that may be namea. Lntries are not named but are uniquely identified by a key, i.e. the contents of particular fielos.

A certain tamiliarity with the relational model is assuneo on the reacer's part. Only its intereretation by a machine will be exanined here.

\subsection{Relational algeora}

ubjects

A attributes naming a set of objects (comain)

an reletions 
$R^{n}\left(A_{1}, A_{2}, \ldots, A_{n}\right) \subseteq A_{1} \times A_{2} \times \ldots \times A_{n}$

EXAMPIE: SUPPLIER (SUPPEIERNR, NAME, LOC), KEY=SUPPLIERNR

SUPPLIER: SUPPLIERNR NAME LOC

$\begin{array}{lll}1 & \text { Jones } & \text { New York } \\ 2 & \text { Snith } & \text { Chicago } \\ 3 & \text { Connors } & \text { Boston } \\ 4 & \text { thompson } & \text { New York }\end{array}$

Rey attributes are inöicatea; keys may be composite. Hierarcnical ano otner relationships are usually eliminated oy normalization. Hence all relations can be assumea to be normalizea.

$\mathrm{T}^{\mathrm{n}} \in \mathrm{R}^{n}$-tuple.

gperators [We 74]

\section{Standaró relation operators}

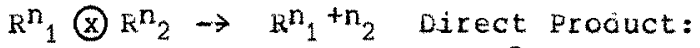

$$
\left\{\left(T^{n_{1}} \cap_{T^{n}} n_{2}\right) \mid T^{n_{1}} \in \mathbb{R}^{n_{1}} \wedge T^{n_{2}} \in R^{n_{2}}\right\}
$$

(n Concatenation operator)

$\left.\begin{array}{lll}R^{n} \cup R^{n} & \rightarrow R^{n} & \text { Union } \\ R^{n} \cap R^{n} & \rightarrow R^{n} & \text { Intersection } \\ R^{n}-R^{n} & \rightarrow R^{n} & \text { Difference }\end{array}\right\} \begin{aligned} & \text { attributes } \\ & \text { must be } \\ & \text { "compatible" }\end{aligned}$

\section{Special operators}

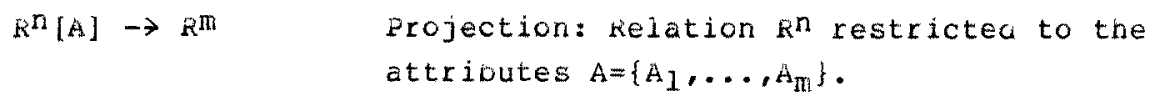

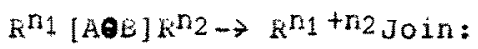

$\left\{\left(T^{n_{1}} \cap T^{n_{2}}\right) \mid\left[\mathrm{n}_{1} \in \mathrm{R}^{\mathrm{n}_{1}} \wedge \mathrm{T}^{\mathrm{n}_{2}} \in \mathrm{R}^{\mathrm{n}_{2}} \wedge \mathrm{TS}_{1}[\mathrm{~A}] \in \mathrm{T}^{\mathrm{n}_{2}}[\mathrm{~B}]\right\}\right.$

where $A, b$ sets of attributes, $\theta$ one of $\{=, \neq,\langle, \leq\rangle,, \geq\}$.

(slight modifications, e.g. natural join, are possible).

$\mathrm{R}^{\mathrm{n}}[\mathrm{A} \theta \Theta] \rightarrow \mathrm{R}^{\mathrm{n}} \quad$ Restriction: $\left\{\mathrm{T}^{\mathrm{n}} \mid \mathrm{T}^{\mathrm{n}} \in \mathrm{R}^{\mathrm{n}} \times \mathrm{T}^{\mathrm{n}}[\mathrm{A}] \Theta \mathrm{T}^{\mathrm{n}}[B]\right\}$

where $A, B, O$ as above.

$\mathrm{R}^{\mathrm{n}}[\mathrm{A} \div \mathrm{B}] \mathrm{R}^{\mathrm{n}} \rightarrow \mathrm{R}^{\mathrm{m}} \quad$ Division: $[\mathrm{CO} 71], \mathrm{P} .74$. 
Control mechanjsm (kelational algebrä)

Since all operators nave been defined as infix operators, "programs" are tormed by linear sequences of operators and operands rather than by nested expressions. for an example see sec. 5.3 .

5.3 kelational calculus (ALHA)

In place of relation algeara coco proposes an appliea preaicate calculus (relational calculus), ana proceeäs to show tnat any expression in tre relational calculus (alpha-expression) may be reduced to an equivalent relation algebraic expression.

Alphabet for the calculus:

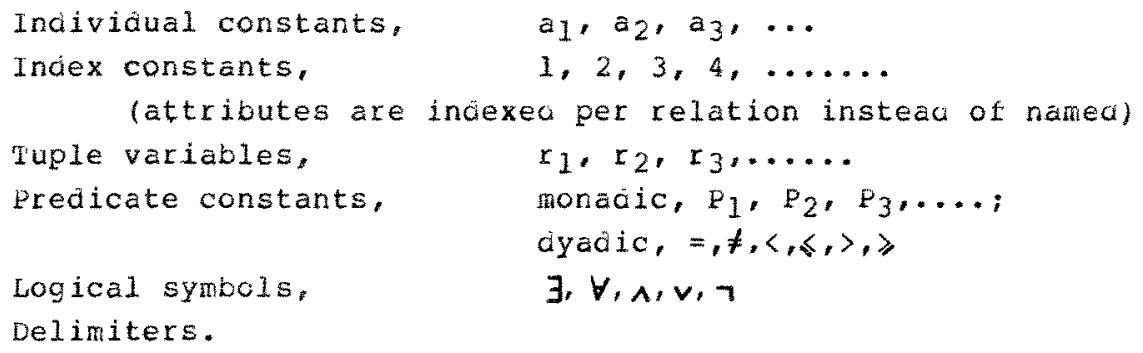

Delimiters.

Simple alpha-expressions have the form

$\left(t_{1}, t_{2}, \ldots, t_{k}\right): w$

where - w a well-formed formula,

- $t_{i}$ distinct terms consisting of an indexea or non-inoexed tuple variable,

- the set of tuple variables occurring in $t_{1}, \ldots t_{k}$ is precisely the set of tree variables in $w$.

ixample: Alpna-expression for "tino the name and location of all suppliers each of whom supelies all projects":

$\left(r_{1}[2], r_{2}[3]\right):$

$$
\mathrm{P}_{1} \mathrm{r}_{1} \wedge \forall \mathrm{P}_{2} \mathrm{r}_{2} \exists \mathrm{P}_{2} \mathrm{r}_{3}\left(\left[\mathrm{r}_{1}[1]=\mathrm{r}_{3}[1]\right) \wedge\left(\mathrm{r}_{3}[3]=\mathrm{r}_{2}[1]\right)\right)
$$

After reduction to relation algebra:

$$
\begin{aligned}
& s_{1}=k_{1} \\
& S_{2}=R_{2} \\
& \mathrm{~s}_{3}=\mathrm{R}_{3} \\
& S=s_{1} \otimes s_{2} \otimes s_{3} \\
& \mathrm{~T}_{3}=S[1=6] \cap S[8 \neq 4] \\
& \mathrm{T}_{2}=\mathrm{I}_{3} \quad[1,2,3,4,5] \\
& \mathrm{T}_{1}=\mathrm{T}_{2}[(4,5) \div(1,2)] \mathrm{s}_{2}
\end{aligned}
$$


$I=I_{1}[2,3]$

ALeria is a Ianguage for alpha expressions taat is signtiy more appealing to the user than the predicate form shown above. Ine example may be reformulatea in ALPhA as

KANGE SUPPLTER L

RANGE PKOJECT

KANGE SUERLY K

GEL W (L.NAME, L.LOC):

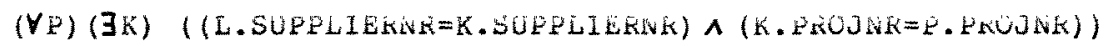

or, equivalently (order of quantifiers must be liaintained!),

KANGE SUPPLIER L

RANGE PROJECT P ÄLE

RANGE SUPPLY $K$ SOME

GET W (L.NAME, L.LOC) :

$(L \cdot$ SUPPLIERNE $=K$.SUPPLIERNK $) \wedge($ K.PROJNR $=$ P.PROJNK $)$

\subsection{Higher levels}

ror reasons similar to the ones in chs. 3 and 4 languages have been devised that do not have to rely on a user"s tormal training. une language of this kina is SquARi [to 74] which nas been shown to de requcible to the relational calculus. However, the view of relations offerec by SQUARE is different from that offered by ALPHA:

(i) Scan a column or columns of a table looking tor a value or a set of values (as opposed to inspecting one row atter another).

(ii) for each such value found examine the corresponaing row anc elenents of given columns in this row.

SQUARE statements are of a form such as ("oisjunctive mapping")

$B^{R_{A}}(S)$

(read: "find $B$ of $R$ where $A$ is $S "$ ) that cefines a mapping such that $R$ is a relation, $A$ and $E$ are sets of attributes (ciomain ana range, respectively), $S$ is an argument that may itself be an expression. other forms, e.g. for projection, conjunctive ana n-ary mappings, nave a similar appearance.

Example: NAMEEHP DEPT ("TOY')

stanas for "Fina tre names of employees in the toy cepartment". 
More recently attempts nave been reporteo tnat allow a user to engage a relational data base systemi in a cialog lounaed on natural Englisa [Co 74]. The approacn aiflers arastically irom the ones uiscusseo in chs. 3 anc 4 in that a truly two-way cominumication is envisioned.

\subsection{Comment}

It has been shown that botn ALPtiA and SQuAkt are equivalent to the relational algebra, i.e. any query expressible in relation algebra is expressible in ALPKA and in SQUAKE, and vice versa. bence ALPHA and SQOARE are themselves equivalent. Equivalence is a symetric relation. The condition on the succession of abstract machines does not precluae equivalence, the definition of the hierarchy by restriction however does. From the point of user sopnistication a hierarchy could stili be given as relational algebra - ALPhA - SQUARE (in the cirection of increasing level). Inis incicates that further refinement on the notion of hierarcny is necessary.

\section{Conclusions}

There are some striking similarities between the examples of cns. 3,4 and 5 ;

- In each the lowest level has been well formalizea.

- All rely on quantification as a means for builaing complex expressions.

- All tend towards natural language on their higher levels.

- All three systems have been implementeo ano founc some application.

On the otner hand, only one of then (ch.5) so far attemptea to provide a less formal but still stylized language on an intermeaiate level. Experiences indicate that, at least in some well-defined situations, tnis may be necessary with the kAIFAs system (cn.3) as well.

while a tew examples do not constitute proof, at the very least they ao suggest that nierarcnies of user languages could meet the objectives mentionea in the introduction. Of course, the relationship between successive levels will have to be made mucn more precise, as nas been indicateo belore. furthermore, nigher levels imply a numoer of successive translations, ano techniques must be explored to measure and perhaps raise the eticiency of nigher levels. Kinally, the paper did not attend to the critical question what form the root snould take; this appears to be a largely unsolvea problem. 
Acknowledgement. The author is grateful to G.Goos for carefully reading the manuscript and making helpful suggestions.

\section{References}

[Ab 74] J.R.Abrial, Data Semantics, in [K] 74], 1-59

[Bo 74] R.F.boyce, D.D.Chamberlin, W.F.King, M.Mammer, Specifying Queries as felational Expressions, in $[K 174], 169-176$

[Bu 72] Burroughs Corp., \$6700/7700 Executive System Programming Language (ESPOL), Information Manual, 1972

[Co Tl] E.F.Codd, A Relational Hodel for Large Shared Data Eanks, Comm.ACH $13(1970)$, No.6, 377-387

[Co 72] E.F.Coca, Relational Completeness of Data base sublanguages, in: K. kustin (eó), Data Base Systems, Courant Computer Science Symp., prentice-fiall, Inc. 1972, 65-98

[Co 74] E.F.Coca, Seven Steps to Rendezvous with the Casual User, in $[\mathrm{KI} 74], 179-199$

[Col 68] L.S.Coles, An Online Question-Answering System with Natural Language and Pictorial Input, Proc. 23ra Natl. ACM Conf. $(1968), 169-181$

[Go 73] G.Goos, Hierarchies, in F.L.eauer (ed), Advanced Course on Software Engineering, Lecture Notes in Econ. and Wath. Systems, vol. $81,29-46$

[Gr 69] C.C.Green, The Application of theorem proving to Question-Answering Systems, Tech. Fee. No. CS138, Stanforà Univ. 1969

[KI 74] J.K.KIimbie, K.L.Koffeman (és), Data Base Management, Nortn-Eolland Publ. Co. 1974

[Kr 75] K.D.kraegeloh, p.C.Lockemann, Hierarchies of Data base Languages: An Example, Information Systems (in print)

[Su 74] B.Sundgren, Conceptual founation of the Infological Approach to Data Bases, in $[K \perp 74], 61-94$

[SI 74] ACM SIGPLAN Symposium on Very high Level Languages, March 1974, ACH, New York 1974 
[We 74] H.Wedekina, Data Dase Systerns I, BI-Wissenschattsverlag, Reine Informatik, vol.16, 1974 (in German)

IWi 68] N.Wirth, PL360, A programing Language tor the 360 Computers, Journ.ACH1 $15(1968)$, No.1, 37-74

[Wo 68] W.A.woods, procedural Semantics for a Question-Answering Machine, Eroc. AfTPs Fall Joint Comp.Conf. $33(1968)$, $457-471$

[Wo 73] W.A.wooas, erogress in Natural Language understanang - an Application to Lunar Geology, proc. AfIHs Nati.Comp.cont. $42(1973), 441-450$ 